\title{
Microstructural Analysis of the Influence of Ecap on the Pure Nb Rolling Plane
}

\author{
Rodrigo E. Pereira ${ }^{1}$, Jefferson Fabrício C. Lins ${ }^{1}$, Priscila S. N. Mendes ${ }^{1}$, \\ Patrícia S. N. Mendes ${ }^{1}$, Willie R. Prudente ${ }^{1}$, Rodrigo P. Siqueira ${ }^{1}$ \\ ${ }^{1}$ Department of Metallurgical Engineering, Federal Fluminense University, Volta Redonda, RJ, Brazil.
}

\begin{abstract}
Starting From a sample of pure and pre-deformed niobium by cold rolling a severe plastic deformation process was performed using ECAP (equal channel angular pressing) in order to verify the evolution and distibution of the deformation structures and of hardness in the lamination plane of the material. To make the analysis were used: the Scanning Electron Microscope-SEM, optical microscope and a hardness map to have a better view of how homogeneous or heterogeneous a process is in relation to the other. After comparison it was seen that the process through ecap uniformized the microstructure and hardness of the material.
\end{abstract}

Keywords: cold rolling, deformation substructures, Ecap

\section{INTRODUCTION}

Niobium is a metal with properties of very interesting for engineering. Besides being refractory, niobium has excellent corrosion resistance, good ductility, biocompatibility and also the ability to form superconducting alloys. On the other hand, in applications that require a lot of mechanical effort as in the case of structural elements, its application becomes limited due to low mechanical resistance, something about $200 \mathrm{MPa}$ [1]. In this aspect the processing by equal channel angular pressing (Ecap) becomes one of the processes that may be interesting for this type of material increase its resistance without greatly harming the potential of some of its properties, such as in the hardening by addition of alloying elements [2].

The deformation processes by Ecap are formally defined as metal forming methods in which the material is submitted to large severe deformations without, however, significantly changing the dimensions of the material leading to an intense refinement by fragmentation of the grains, creating materials with even nanometric granulometry [3]. Such a process, even at room temperature, can increase the strength of the material significantly without greatly impairing its ductility, which is not possible in conventional forming processes such as rolling and forging [2]. Then, from this premise, understanding the importance of its effects on various strands is a challenge for the academic world to effectively contribute to its wider and more varied use. In this work, we sought better understand the effect of the Ecap process on the Microstructure and hardness of the material when pre-deformed by cold rolling.

The deformation microstructures resulting from the plastic deformation processes are very heterogeneous, which causes the appearance of the most diverse deformation structures such as bands deformation, bands transition and shear bands [4][5]. The deformation bands are regions within the same grain that performed different rotations, being delimited by the transition bands and that can be found quite often in materials that present high energy of stacking defect (EDE) and coarse grains, and can even be visualized in metals which have experienced slight deformations [4][5]. The shear bands are regions that have experienced strong localized sliding and are not limited to regions within the grain forming angles in a range of 30 to 60 degrees in relation to the effort direction and are easily visualized by the optical microscope [5].

\section{EXPERIMENTAL}

\subsection{Material}

The starting material used in the ecap was a pure niobium sample and laminated in multiple passes on a rolling mill Fenn 4-105 two-high / fourhigh with maximum useful width of $380 \mathrm{~mm}$ [6]. This material has been reduced $80 \%$ in its thickness and its chemical composition is distributed as shown in table 1:

Table 1- Chemical composition of the sample (values expressed in ppm).

\begin{tabular}{|l|l|l|l|l|l|l|}
\hline Elemento & $\mathrm{W}$ & $\mathrm{Fe}$ & $\mathrm{Al}$ & $\mathrm{Ta}$ & $\mathrm{O}$ & $\mathrm{N}$ \\
\hline Composição & $\mathrm{ND}^{*}$ & $\mathrm{ND}$ & $<200$ & $<2000$ & $<50$ & $<30$ \\
\hline Subscript * & \multicolumn{1}{|l|}{ Not detected } \\
\hline
\end{tabular}

It is importante to record that the material used in this work was oligocrystalline before undergoing cold rolling process and that the analysis was limited in a small region of the rolling plane (see fig.1). In Fig. 1 is shown the image of two samples belonging to the same set, sample A was 
chosen for ECAP processing and its corresponding $B$ was analyzed as received.

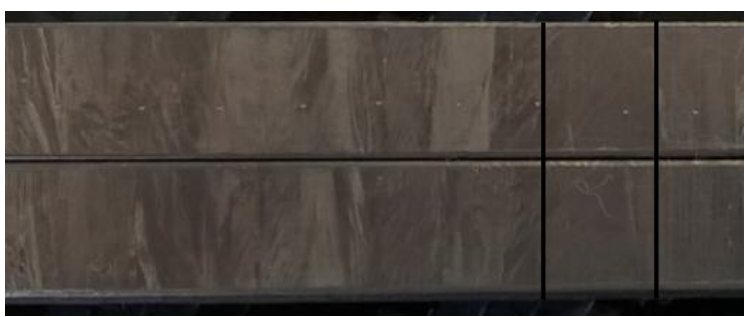

Figura 1- Image of the studied section.

\subsection{Methods}

\subsubsection{Processing by Ecap}

In the processing by ECAP a universa mechanical testing machine was used EMIC DL-60 With maximum load capacity of $600 \mathrm{kN}$, A split two-part tool steel die de $10 \times 10 \mathrm{~mm}$ Forming an angle of $90^{\circ}$ and arc of curvature about $37^{\circ}$ and a Lubricant based on $\operatorname{MoS} 2$. The sample orientation scheme is shown in Fig.2. The directions ND, LD, $\mathrm{RD}$ and ED are designated as normal, longitudinal, rolling and extrusion directions, respectively.

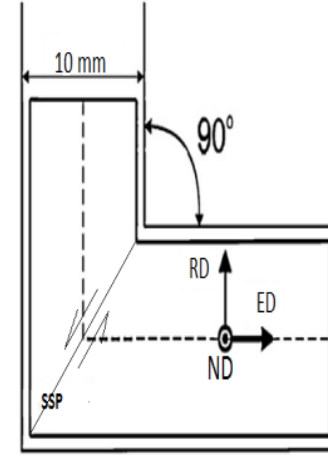

(a)

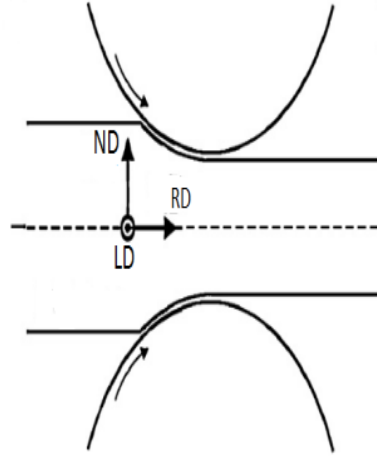

(b)
Figure 2: Schematic orientation of the sample during processing.(a) represents the disposition of the sample in the matrix of ecap and (b) during the rolling.

\subsubsection{Microhardness}

The Vickers hardness measurements were performed aiming to determine the hardness of the sample before and after ECAP. 225 microhardness measurements were performed to in order to generate a map in the Origin ${ }^{\circledR} 6.0$ software. For these measurements, a Shimadzu microdurometer model HVM-2T was used. The Fig. 3 shows the schematic of how the hardness distribution was made along the studied area.

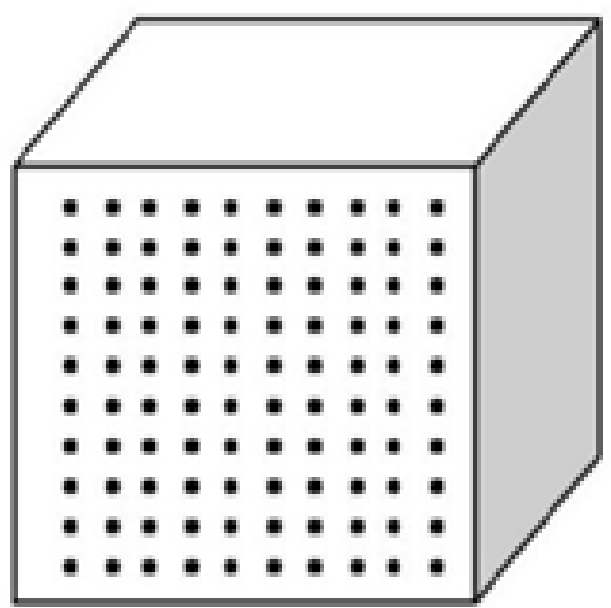

Figure 3: Distribution of hardness in the studied area.

\subsubsection{Metallographic preparation}

The metallographic preparation to reveal the microstructural was carried by sanding, polishing and chemical attack. The Sanding was performed using the sandpapers with silicon carbide: 320,400 , $600,800,1000,1200,1500$ and 2500 . The polishing was done with a solution of $100 \mathrm{ml}$ of distilled water, $260 \mathrm{ml}$ of Oxide polishing suspensions (op-s), $1 \mathrm{ml}$ of detergent, $0,5 \mathrm{ml}$ of $\mathrm{HF}$ and $1 \mathrm{ml} \mathrm{HNO} 3$. The chemical attack was done using a solution with 50 $\mathrm{ml}$ of distilled water, $25 \mathrm{ml} \mathrm{HNO} 3$ and $10 \mathrm{ml} \mathrm{HF}$.

\subsubsection{Microscopy}

The images in this work were obtained by a NIKON LV150 optical microscope and the "Stream Basic 8.1" image capture software. In addition to a Scanning electron microscope (SEM) of the type Zeiss EVO MA10 with LaB6 filament.

\section{RESULTS AND DISCUSSION}

\subsection{Microstructural characterization}

Through optical micrography and scanning electron microscopy, the characteristics of the deformation structures in the analyzed materials are shown. Both the sections were heterogeneous regarding the distribution of the substructures. However, in the sample processed by Ecap, a more extensive region of shear bands was found, as shown in Fig. 4 and 5, some tending to align along a preferential direction to the simple shear plane (SSP).

Zhu, in [7], also observed a set of bands oriented preferably at about $45^{\circ}$ in relation to the direction of extrusion, almost parallel to the plane SSP. Moreover according to Zhu, when analyzing these bands oriented was found, based on a study by EBSD, a formation of high angle boundaries (HAGBs) mainly in this region, suggesting a greater shear along the SSP [7]. Stepanov in [8] and Sandim 
in [9], in doing the analysis in that same section also observed this preferential orientation.

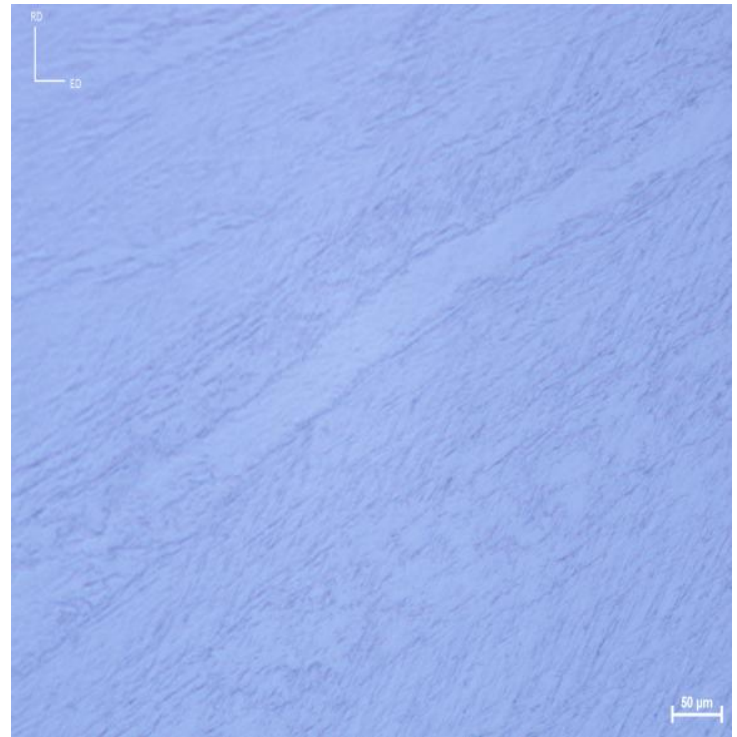

Figure 4: Overview of the deformation substructures obtained by optical microscopy of section RD-ED.

In Fig. 4 is still seen a set of bands, some thinner and some more coarse. From previous studies, we can suggest that these coarser regions may have a low density of discordance inside [7].

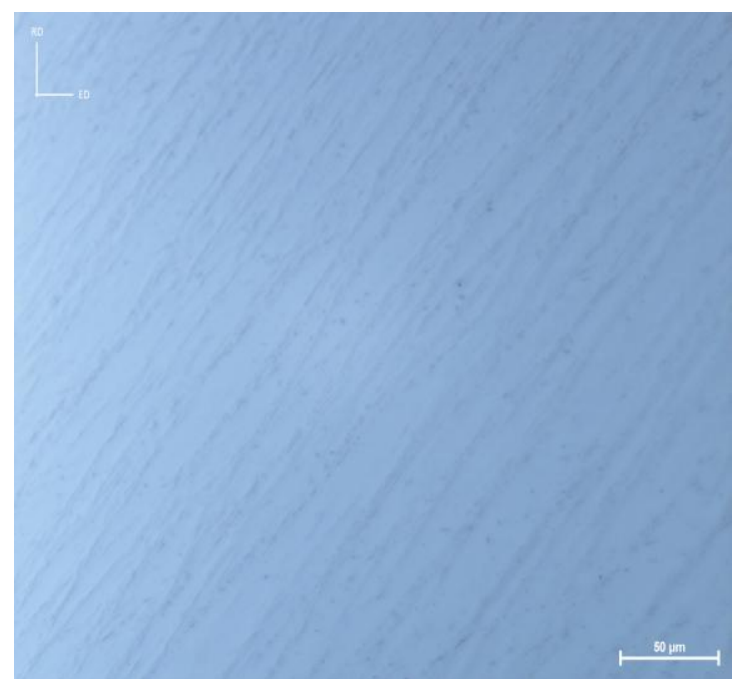

Figure 5: View of regions with preferential orientation in section RD-ED.

Another relevant record to be made is also that found in fig. 6, which shows the result of the microstructural fragmentation process, originated from the numerous rotations suffered by the grains to accommodate the increasing deformations in the material. The dislocations are lodged in the regions of different orientations, resulting in small crystals in the microstructure (subgrains).

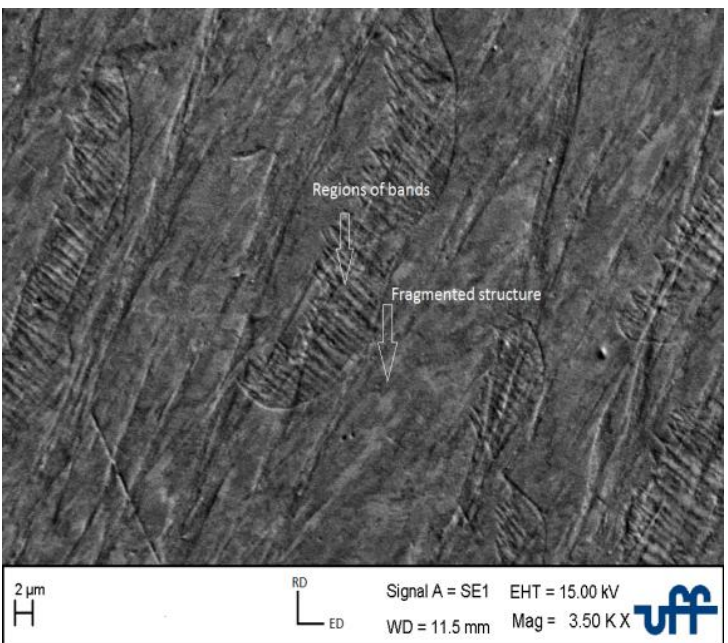

Figure 6: Secondary electron image is obtained through SEM-scanning electron microscopy of section RD-ED

Differently from what was seen in the sample processed by ecap, the laminated material, when investigated, demonstrated a very complex structure and a lot more heterogeneous throughout the section studied, having few regions with some uniformity. LINS, in [6], when recording the characteristics of the deformation substructures for this same material, highlighted the complexity sometimes presented.

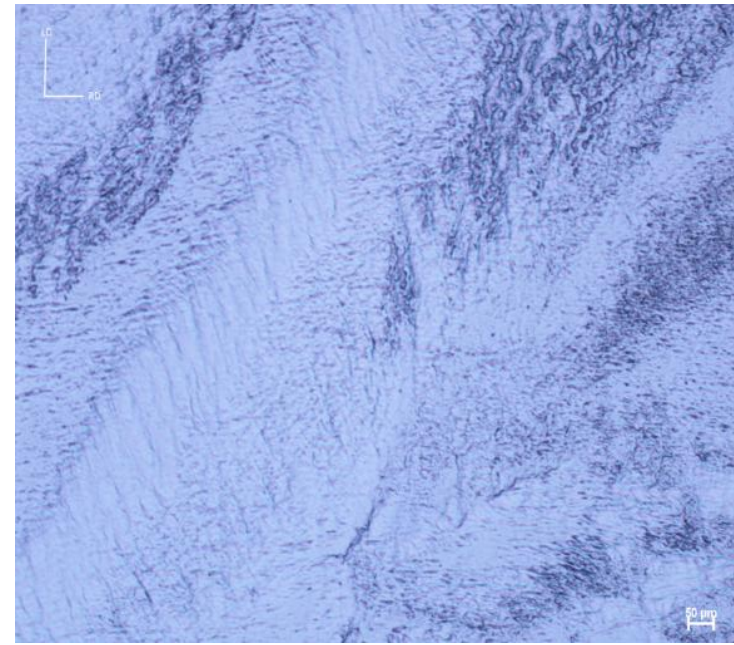

Figure 7: Image of the section RD-LD of the laminated sample obtained by optical microscopy.

The Fig. 7 shows a region of the material where one of these complex parts is visualized, evidencing a small portion of lamellar structures (in fig. 8 this structure is being highlighted in in more detail). 


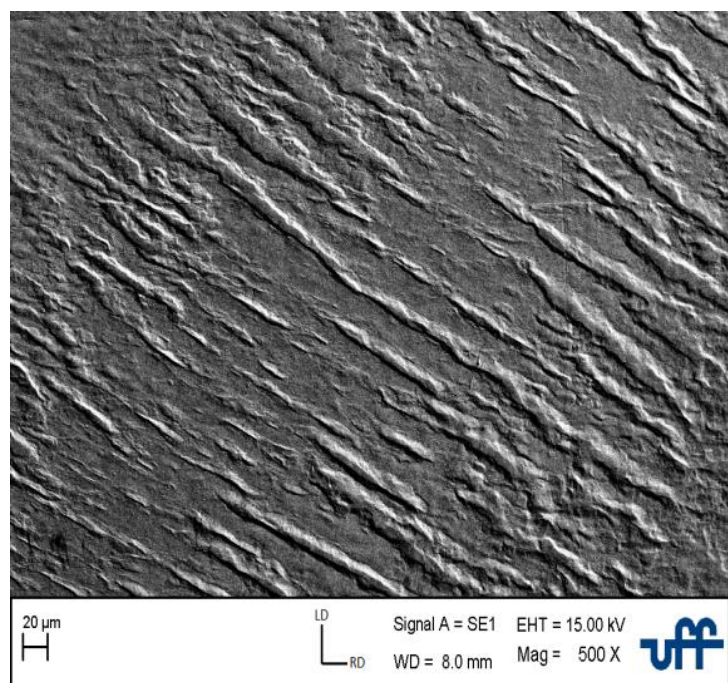

Figure 8: Lamellar region in detail in section RDLD

\subsection{Microhardness vickers}

The hardness values found for the sample processed by rolling with $80 \%$ reduction varied between 98-126 HV, and the mean hardness found was $112 \mathrm{HV}$ with a standard deviation of 5.5. When analyzing the hardness distribution along the section, the behavior found is that of Fig. 9: A very heterogeneous hardness distribution throughout the section.

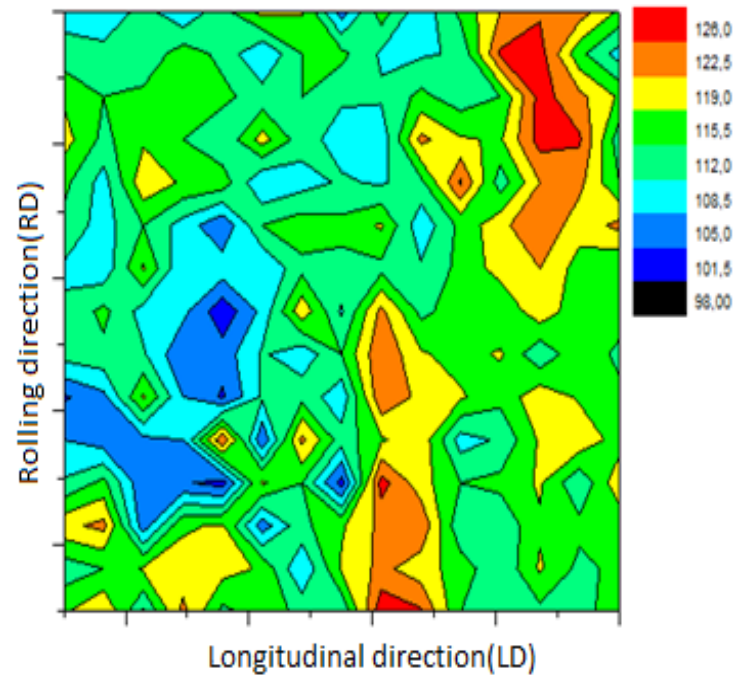

Figure 9: Distribution of longitudinal plane hardness RD-LD.

After going through an ecap processing the material presented hardness values in a hardness range between 100-135, with a mean of $118 \mathrm{HV}$ and an average standard deviation of 4.2. It was noticed that there was no significant increase of hardness when compared to the laminated sample. This behavior is due to the phenomenon of dynamic recovery. This happens because during plastic deformation the movement and increase of the amount of dislocations lead to the increase of interactions and consequently annihilation of dislocations. When the high EDE metals are deformed, the dislocations are almost nondissociated, further facilitating the sliding and, consequently, the annihilation [2]. In this case, as the niobium has high EDE, about $537 \mathrm{~mJ} / \mathrm{m}^{2}$, this contributes greatly to a high dynamic recovery even at room temperature [2].

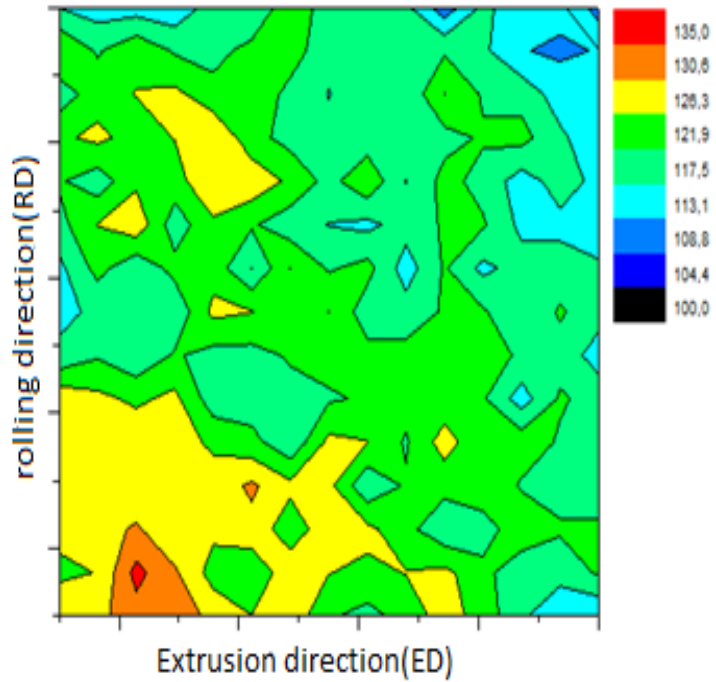

Fig. 10: Distribution of hardness of the longitudinal plane ND-DE.

It is also seen, when looking at the map of hardness in Fig. 10, a hardness distribution is also found to be quite heterogeneous, however, when compared to the rolling process, it has a more homogeneous hardness distribution.

It is important to note that in both samples the heterogeneity in the distribution of hardness is due to the fact that the formed substructures are randomly distributed throughout the material due to the deformation process that occurs in a distinct way throughout the material. According to results obtained by LINS, in [6], in similar material, this distribution inequality of the substructures was verified throughout the material, even in regions between two adjacent grains this difference is clearly observed.

\section{CONCLUSION}

In the obtained results it was possible to verify a greater uniformity in the microstructure of deformation processed by ecap when compared to the laminated sample, a result that had consequence in the mechanical properties of hardness. Therefore, it can be concluded that in the section containing the rolling plan the material processed via ecap caused a more uniform microstructure and a better distribution of the hardness in the material. 
In order to obtain a better result about the effective benefit of this processing route it is necessary to study the other sections of the material, in addition to a greater depth in microstructural analysis. In spite of this, the result found provides an indication that laminating the material and proceeding with the processing via ecap may be an interesting processing route for a scientific estudy future.

\section{REFERENCES}

[1]. LANGDON, T.G. The processing of ultrafine-grained materials through the application of severe plastic deformation. Journal of Materials Science, v.42 ,p.33883397,2007.

[2]. BERNARDI,H.H Processamento $e$ caracterização microestrutural de nióbio deformado plasticamente por extrusão em canal angular. Tese de doutorado. Faculdade de engenharia química de Lorena-USP, 2009.

[3]. VALIEV, R.Z., LANGDON, T.G., Principles of equal-channel angular pressing as a processing tool for grain refinement. Progress in Materials Science, v. 51, pp . 881-981, 2006

[4]. D.Kuhlmann regular deformation bands and the LEDS hypothesis. Acta materials, v.47, pp.11697-1712, 1999.

[5]. N.Hansen Polycrystalline strengthening Mettal. Trans V.16A, pp. 2167-2190, 1985.

[6]. LINS, J.F.C Estudo da recuperação e recristalização do nióbio com microestrutura oligocristalina laminada a frio. Dissertação de mestrado. Faculdade de engenharia química de Lorena, 2001.

[7]. L.ZHU,M.SEEFELDET,B.VERLINDEN.

Three $\mathrm{Nb}$ single crystals processed by equal-channel angular pressing-Part I: Dislocation Substructure . Acta Materialia ,v.61,pp 4490-4503,2013.

[8]. N.D Stepanov, A.V.Kuznetsov, G.A. Salishchev, G.I.Raab,R.Z. Valiev. Effect of cold rolling on microstructure and mechanical properties of copper subjected to ECAP with various numbers of passes. Materials science and engineering A. v.554, pp105-115,2012.

[9]. SANDIM,H.R.Z;BERNARDI,H.H;VERLI NDEN, B; RAABE,D. Equal channel angular extrusion of niobium single crystals. Materials science and engineering A.v.467, pp. 44-52, 2007. 